\title{
Synthesis of nitrogen-doped zinc oxide particles by thermal decomposition of mixture between zinc peroxide aqueous sol and ammonium salts
}

\author{
Naofumi UEKAWA ${ }^{\dagger}{ }^{\dagger}$ usuke MITANI, Takashi KOJIMA and Kazuyuki KAKEGAWA \\ Graduate School of Engineering, Chiba University, 1-33, Yayoi-cho, Inage-ku, Chiba-shi 263-8522
}

\begin{abstract}
The nitrogen-doped $\mathrm{ZnO}$ particles were prepared by heating a mixture of an ammonium salt and the aqueous sol of zinc peroxide nanoparticles. In the case that the sol of zinc peroxide nanoparticles were mixed with ammonium nitrate in the sol, nitrogen-doped $\mathrm{ZnO}$ particles were obtained by heating the mixture at $573 \mathrm{~K}$ for $1 \mathrm{~h}$ in the air. The obtained particles showed characteristic Raman peaks that can be assigned to the nitrogen-related local vibrational mode. The strength of the UV-VIS absorption peak, which corresponds to the nitrogen-related impurity state, also increased with increases in the mixed amount of ammonium nitrate $\left(\mathrm{NH}_{4} \mathrm{NO}_{3}\right)$. The results of iodometric titration also showed the formation of acceptor states in the obtained nitrogen-doped $\mathrm{ZnO}$ particles. The nitrogen-doping successively occurred when the peroxo ions $\left(\mathrm{O}_{2}{ }^{2-}\right)$ in the zinc peroxide did not react with the anions in the ammonium salts as an oxidizing agent.
\end{abstract}

(02009 The Ceramic Society of Japan. All rights reserved.

Key-words : Zinc oxide, Sol, Nitrogen doping, Zinc peroxide

[Received November 10, 2008; Accepted January 15, 2009]

\section{Introduction}

Many of the characteristics of zinc oxide $(\mathrm{ZnO})$, including its piezoelectricity, photoluminescent (PL) characteristics, and semiconductivity, have been applied to a variety of electrical devices. ${ }^{1,2)}$ In particular, $\mathrm{ZnO}$ functions as a wide-gap oxide semiconductor. Doping of $\mathrm{Al}^{3+}$ ions and the presence of the oxygen vacancies in the $\mathrm{ZnO}$ lattice produce donor levels, producing n-type semiconductivity. ${ }^{3)}$ On the other hand, in recent years, the preparation method for p-type $\mathrm{ZnO}$ has been intensively investigated since it can be used for the development of shortwavelength optical devices. ${ }^{4), 5)}$ Nitrogen $(\mathrm{N})$ doping by the substitution of nitrogen for oxygen $(\mathrm{O})$ is an effective method for obtaining p-type $\mathrm{ZnO}{ }^{6), 7)}$ Theoretical calculations have shown that nitrogen-doping produces a shallow acceptor level approximately $0.1 \mathrm{eV}$ above the valence band in $\mathrm{ZnO} .{ }^{8)}$ However, there are many difficulties in obtaining p-type $\mathrm{ZnO}$, whose semiconductivity depends with great sensitivity on the doping conditions. ${ }^{8)}$ Therefore, the development of simple and effective preparation methods for nitrogen-doped $\mathrm{ZnO}$ is a very important issue.

Various preparation methods for nitrogen-doped $\mathrm{ZnO}$ material have been reported. The MOCVD methods can be used for preparation of the film samples. Wang et al. have shown the decomposition of diethyl zinc on a substrate at $873 \mathrm{~K}$ under an atmosphere of a mixed gas of $\mathrm{N}_{2}$ and $\mathrm{O}_{2}{ }^{9}{ }^{9}$ Zhao et al. have employed a spray pyrolysis method to prepare nitrogen-doped $\mathrm{ZnO}$ film by decomposition of zinc acetate and ammonium acetate in a $\mathrm{N}_{2}$ atmosphere. ${ }^{10)}$ Varghese et al. have obtained nitrogen-doped $\mathrm{ZnO}$ nanoparticles using a solvothermal method. ${ }^{11)} \mathrm{Li}$ et al. have investigated the semiconductivity of the $\mathrm{ZnO}$ particles obtained by decomposition of various precursors such as zinc

Corresponding author: N. Uekawa; E-mail: uekawa@ faculty.chiba -u.jp peroxide $\left(\mathrm{ZnO}_{2}\right)$ and zinc nitrate. ${ }^{6}$

The authors have previously shown that low-temperature heating of zinc peroxide nanoparticles at around $500 \mathrm{~K}$ results in $\mathrm{ZnO}$ nanoparticles with oxygen vacancies. ${ }^{12)}$ Substitution of nitrogen for the oxygen vacancies in the $\mathrm{ZnO}$ lattice is considered to be effective in efficiently obtaining nitrogen-doped $\mathrm{ZnO}$. Furthermore, the authors have also developed the solution process to prepare the stable aqueous sol of zinc peroxide nanoparticles, which can form the homogeneous mixture of the nitrogen source for the nitrogen doping and the zinc peroxide nanoparticles. The aqueous sol of the zinc peroxide nanoparticles would then be appropriate as precursors of the nitrogen-doped $\mathrm{ZnO}$. Furthermore, the application of the aqueous solution and sol of the metal peroxides to inorganic reactions is an attractive prospect. Therefore, in this study, the heat treatment of a mixture between zinc peroxide aqueous sol and ammonium salts in air was examined to obtain nitrogen-doped $\mathrm{ZnO}$ particles, and application of aqueous sol of the zinc peroxide nanoparticles for nitrogen doping was examined.

\section{Experiments}

\subsection{Preparation of zinc peroxide nanoparticles}

The sols containing zinc peroxide nanoparticles were prepared our previously reported method. ${ }^{12), 13)}$ To obtain zinc hydroxide $\left(\mathrm{Zn}(\mathrm{OH})_{2}\right)$ precipitate, $100 \mathrm{ml}$ of $\mathrm{Zn}\left(\mathrm{NO}_{3}\right) \cdot 6 \mathrm{H}_{2} \mathrm{O}$ aqueous solution $(0.1 \mathrm{~mol} / \mathrm{l})$ and $100 \mathrm{ml}$ of $\mathrm{NaOH}$ aqueous solution $(0.1 \mathrm{~mol} / \mathrm{l})$ were mixed. The precipitate was separated from the solution by a centrifuge at 3000 r.p.m. for $5 \mathrm{~min}$. The obtained $\mathrm{Zn}(\mathrm{OH})_{2}$ was dispersed into distilled water and was again separated by a centrifuge. This procedure was repeated 3 times, and the impurities in the precipitate were removed. The $\mathrm{Zn}(\mathrm{OH})_{2}$ was then dispersed in $50 \mathrm{ml}$ of $\mathrm{H}_{2} \mathrm{O}_{2}$ aqueous solution to a concentration of $1 \mathrm{~mol} / \mathrm{l}$. The dispersed solution was heated at $348 \mathrm{~K}$ for $2 \mathrm{~h}$ in a closed glass vessel $(200 \mathrm{ml})$. The resultant solution was a translucent sol of the zinc peroxide nanoparticles. 


\subsection{Preparation of nitrogen-doped $\mathrm{ZnO}$ particles}

The ammonium nitrate $\left(\mathrm{NH}_{4} \mathrm{NO}_{3}\right)$ was dissolved into the zinc peroxide aqueous sol. The molar ratios of $\left[\mathrm{NH}_{4} \mathrm{NO}_{3}\right] /\left[\mathrm{Zn}^{2+}\right.$ ion in the zinc peroxide sol] were adjusted to $0,0.05,0.1,0.15,0.2$ and 0.25 . The zinc peroxide aqueous sol with $\mathrm{NH}_{4} \mathrm{NO}_{3}$ was dried at $348 \mathrm{~K}$ for $12 \mathrm{~h}$. The obtained powder of the mixture of the zinc peroxide nanoparticles and $\mathrm{NH}_{4} \mathrm{NO}_{3}$ was heated at temperatures ranging from $473 \mathrm{~K}$ to $1073 \mathrm{~K}$ for $1 \mathrm{~h}$ in air. Furthermore, the same preparation procedure to obtain the nitrogen-doped $\mathrm{ZnO}$ was carried out by using other ammonium salts such as ammonium chloride $\left(\mathrm{NH}_{4} \mathrm{Cl}\right)$, ammonium acetate $\left(\mathrm{NH}_{4}\left(\mathrm{CH}_{3} \mathrm{COO}\right)\right)$, and ammonium oxalate $\left(\left(\mathrm{NH}_{4}\right)_{2} \mathrm{C}_{2} \mathrm{O}_{4}\right)$, which were substitute for the $\mathrm{NH}_{4} \mathrm{NO}_{3}$

\subsection{Characterization}

The structure of the obtained powders was characterized by means of X-ray diffraction (XRD). The XRD patterns of the samples were measured by using Mac Science Co., Ltd. M18X-HF-SRA. $\mathrm{Cu}$ was used as the target $(\mathrm{Cu} \mathrm{K} \alpha, 40 \mathrm{kV}, 200$ $\mathrm{mA})$. An optical system of $\mathrm{SS}=1^{\circ}, \mathrm{DS}=1^{\circ}, \mathrm{RS}=0.15 \mathrm{~mm}$ and a graphite monochromator was used. Raman spectroscopy (JASCO Co., NRS1000) was used to determine the doped nitrogen atoms. The optical absorption spectra of the obtained $\mathrm{ZnO}$ powder were recorded (JASCO Co., V-560). The particle shape was observed by field emission-SEM (FE-SEM Hitachi, Ltd., S4700).

Iodometric titrations were employed to determine the number of acceptor states in the obtained nitrogen-doped $\mathrm{ZnO}$ particles. ${ }^{6}$ ) Iodide $\left(\mathrm{I}^{-}\right)$is oxidized by acceptor states as following equation: $3 \mathrm{I}^{-}+2\left(\right.$ acceptor $\left.^{+}\right) \rightarrow \mathrm{I}_{3}^{-}$. The number of acceptor states can be estimated by the number of the released triiodide $\left(\mathrm{I}_{3}{ }^{-}\right)$ions, which was titrated with sodium thiosulfide. ${ }^{14)}$ The number of acceptor states was calculated from the amount of the used trisulfide. The detailed titration process was as follows. $5 \mathrm{ml}$ of 0.5

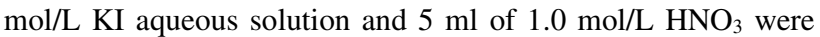
added on $0.2 \mathrm{~g}$ of nitrogen-doped $\mathrm{ZnO}$ powders, which were completely dissolved. The whole solution was titrated by using solutions of $0.002 \mathrm{~mol} / \mathrm{L} \mathrm{Na}_{2} \mathrm{~S}_{2} \mathrm{O}_{3}$ and starch solution as an indicator. All the distilled water was boiled used were boiled and cooled under $\mathrm{N}_{2}$ atmosphere. The used flasks were also capped and filled with $\mathrm{N}_{2}$ gas to prevent oxidation of iodide by air.

\section{Results and discussion}

\subsection{Zinc oxide formation by heating mixture of the aqueous sol of zinc peroxide nanoparticles and $\mathrm{NH}_{4} \mathrm{NO}_{3}$}

Figure 1 shows the XRD patterns of the particles obtained by heating the mixture of the aqueous sol of zinc peroxide nanoparticles and $\mathrm{NH}_{4} \mathrm{NO}_{3}$ for $1 \mathrm{~h}$ when the molar ratio of $\mathrm{NH}_{4} \mathrm{NO}_{3} / \mathrm{Zn}^{2+}$ was 0.1. Figure 1(a) shows the XRD pattern of the mixed powder of the zinc peroxide nanoparticles and $\mathrm{NH}_{4} \mathrm{NO}_{3}$. The XRD peaks in the Fig. 1(a) can be assigned to zinc peroxide, and no XRD peaks corresponding to $\mathrm{NH}_{4} \mathrm{NO}_{3}$ can be observed. These results suggest that the crystallized particles of $\mathrm{NH}_{4} \mathrm{NO}_{3}$ which can be detected by the XRD measurement was not formed in the obtained powder during the drying process. When the heating temperature was $473 \mathrm{~K}$, all of the XRD peaks could be assigned to $\mathrm{ZnO}$, as shown in Fig. 1(b). Then, $\mathrm{ZnO}$ particles were obtained by heating the mixed powder of the zinc peroxide nanoparticles and $\mathrm{NH}_{4} \mathrm{NO}_{3}$ to more than $473 \mathrm{~K}$. The half width of the $\mathrm{ZnO}$ (1 $\left.\begin{array}{ll}1 & 0\end{array}\right)$ plane at $31.8^{\circ}$ was decreased when the heating temperature increased from $473 \mathrm{~K}$ to $573 \mathrm{~K}$, as shown in Figs. 1(b) and (c). On the other hand, the full width at half maximum (FWHM) of the $\mathrm{ZnO}\left(\begin{array}{lll}1 & 0 & 0\end{array}\right)$ plane did not change when the heating tem-

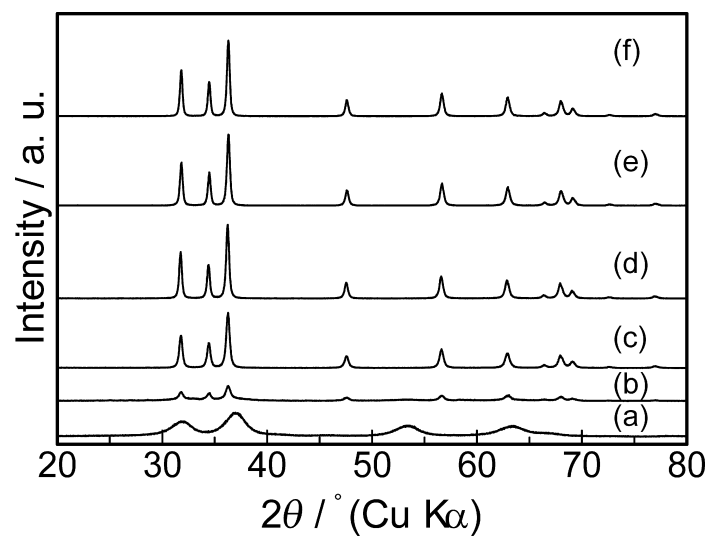

Fig. 1. XRD patterns of the particles obtained by heating the mixture of zinc peroxide nanoparticles and $\mathrm{NH}_{4} \mathrm{NO}_{3}$ for $1 \mathrm{~h}$. The molar ratio of $\mathrm{NH}_{4}{ }^{+} / \mathrm{Zn}^{2+}$ was 0.1 . The heating temperatures were: (a) without heating, (b) $473 \mathrm{~K}$, (c) $573 \mathrm{~K}$, (d) $673 \mathrm{~K}$, (e) $773 \mathrm{~K}$ and (f) $873 \mathrm{~K}$.

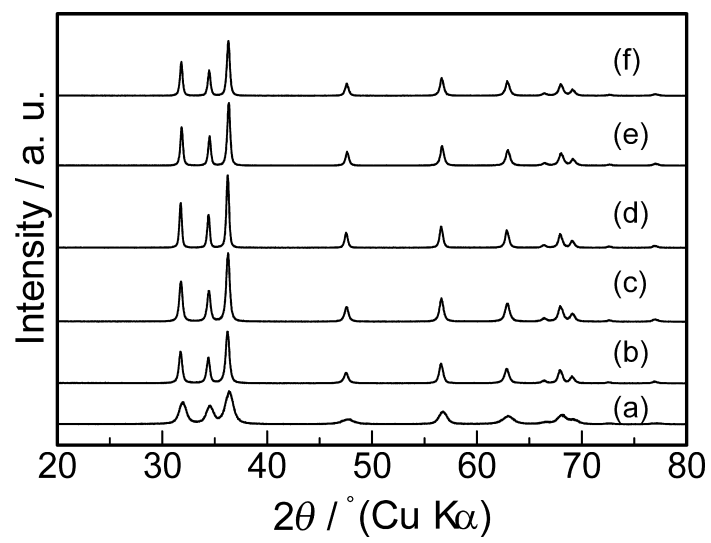

Fig. 2. XRD patterns of the particles obtained by heating the mixture of zinc peroxide nanoparticles and $\mathrm{NH}_{4} \mathrm{NO}_{3}$ at $573 \mathrm{~K}$ for $1 \mathrm{~h}$. The molar ratios of $\mathrm{NH}_{4} \mathrm{NO}_{3} / \mathrm{Zn}^{2+}$ were: (a) 0.05 , (b) 0.1 , (c) 0.15 , (d) 0.2 and (e) 0.25 .

perature was more than $573 \mathrm{~K}$, as shown in Figs. 1(c)-(f). As such, heating to $573 \mathrm{~K}$ appeared to be sufficient to obtain wellcrystallized $\mathrm{ZnO}$ particles.

In order to investigate the effects of the addition of ammonium salts on the formation behaviour of the $\mathrm{ZnO}$ particles, the relation between the molar ratio of $\mathrm{NH}_{4} \mathrm{NO}_{3} / \mathrm{Zn}^{2+}$ and the degree of the crystallization of the obtained $\mathrm{ZnO}$ particles were examined. Figures 2(a)-(f) show the XRD patterns of the particles obtained by heating the mixture of the zinc peroxide nanoparticles and $\mathrm{NH}_{4} \mathrm{NO}_{3}$ at $573 \mathrm{~K}$ for $1 \mathrm{~h}$. The molar ratio of $\mathrm{NH}_{4} \mathrm{NO}_{3} / \mathrm{Zn}^{2+}$ was in the range from 0 to 2.5. All of the XRD peaks can be assigned to $\mathrm{ZnO}$. The FWHM of the $\mathrm{ZnO}\left(\begin{array}{lll}1 & 0 & 0\end{array}\right)$ plane in the Fig. 2(a) was larger than those of the peaks in the Figs. 2(b)-(f). The FWHM of the $\mathrm{ZnO}\left(\begin{array}{lll}1 & 0 & 0\end{array}\right)$ plane in the Figs. 2(b)-(f) did not deepened on the amount of $\mathrm{NH}_{4} \mathrm{NO}_{3}$. These results suggested that the crystallite size of the zinc oxide obtained by heating the mixture of the zinc peroxide nanoparticles and $\mathrm{NH}_{4} \mathrm{NO}_{3}$ was larger than that of the zinc oxide obtained by heating the zinc peroxide nanoparticles. Therefore, the coexistence of the $\mathrm{NH}_{4} \mathrm{NO}_{3}$ affected the degree of crystallization of the obtained $\mathrm{ZnO}$ particles. 


\subsection{Characterization of the nitrogen-doped $\mathrm{ZnO}$ obtained by heating the mixture of the aque- ous sol of zinc peroxide nanoparticles and $\mathrm{NH}_{4} \mathrm{NO}_{3}$}

In order to further examine the details of the effect of the coexisting $\mathrm{NH}_{4} \mathrm{NO}_{3}$ on the decomposition process of the zinc peroxide nanoparticles, the Raman spectra of the obtained particles were obtained. In general, the presence of an oxygen vacancy and the doped nitrogen can be detected by using Raman peaks. Figure 3 shows the Raman spectra of the obtained $\mathrm{ZnO}$ particles by heating the mixture of $\mathrm{NH}_{4} \mathrm{NO}_{3}$ and the zinc peroxide nanoparticles at $573 \mathrm{~K}$ for $1 \mathrm{~h}$ when the molar ratio of $\mathrm{NH}_{4} \mathrm{NO}_{3} / \mathrm{Zn}^{2+}$ was in the range from 0 to 0.2. Figure 3(a) shows the Raman spectrum of the $\mathrm{ZnO}$ particles obtained by heating the zinc peroxide nanoparticles at $573 \mathrm{~K}$ for $1 \mathrm{~h}$ without $\mathrm{NH}_{4} \mathrm{NO}_{3}$. The spectrum in Fig. 3(a) exhibits transitions near $330 \mathrm{~cm}^{-1}, 383 \mathrm{~cm}^{-1}$, and $437 \mathrm{~cm}^{-1}$ shift. The peaks at $330 \mathrm{~cm}^{-1}$ and $437 \mathrm{~cm}^{-1}$ can be assigned to the lattice vibrational mode 2E2 (M) and E2 (high) of $\mathrm{ZnO}{ }^{15)}$ The peak at $383 \mathrm{~cm}^{-1}$ can be assigned to the lattice vibrational mode A1 (TO) mode of $\mathrm{ZnO}^{15}{ }^{15}$ In contrast, new Raman peaks appeared at $275 \mathrm{~cm}^{-1}, 507 \mathrm{~cm}^{-1}$, and $583 \mathrm{~cm}^{-1}$, as shown in Figs. 3(b) and (c), when the mixture of $\mathrm{NH}_{4} \mathrm{NO}_{3}$ and zinc peroxide nanoparticles was heated at $573 \mathrm{~K}$ for $1 \mathrm{~h}$. These peaks correspond to the nitrogen-related local vibration modes. ${ }^{16)}$ Furthermore, the peak intensity, which corresponded to the nitrogen-related local vibration, increased with increase in the molar ratio of $\mathrm{NH}_{4} \mathrm{NO}_{3} / \mathrm{Zn}^{2+}$. According to the Raman spectra, we can conclude that nitrogen-doped $\mathrm{ZnO}$ particles were obtained by heating the mixture of the aqueous sol of zinc peroxide nanoparticles and $\mathrm{NH}_{4} \mathrm{NO}_{3}$. The homogeneous dispersion of $\mathrm{NH}_{4} \mathrm{NO}_{3}$ on the surface of the zinc peroxide nanoparticles played an important role for the nitrogen doping.

When the nitrogen doping successfully occurred, acceptor states should be formed. The acceptor states can accept electrons from iodide $\left(\mathrm{I}^{-}\right)$anions. Then, the number of the acceptor states formed by nitrogen doping can be determined by using iodometric titration method. ${ }^{6}$ ) The number of acceptor states per $\mathrm{Zn}^{2+}$ ion were calculated from the results of iodometric titration. According to the results of the titration, the acceptor states were not detected in the $\mathrm{ZnO}$ particles obtained by heating the zinc peroxide nanoparticles at $573 \mathrm{~K}$ for $1 \mathrm{~h}$. When the nitrogen-doped $\mathrm{ZnO}$ particles prepared by heating the mixture of the zinc peroxide nanoparticles and $\mathrm{NH}_{4} \mathrm{NO}_{3}$ whose molar ratio of $\mathrm{NH}_{4} \mathrm{NO}_{3} /$ $\mathrm{Zn}^{2+}$ were 0.05 and 0.1 , the number of the acceptor states per a

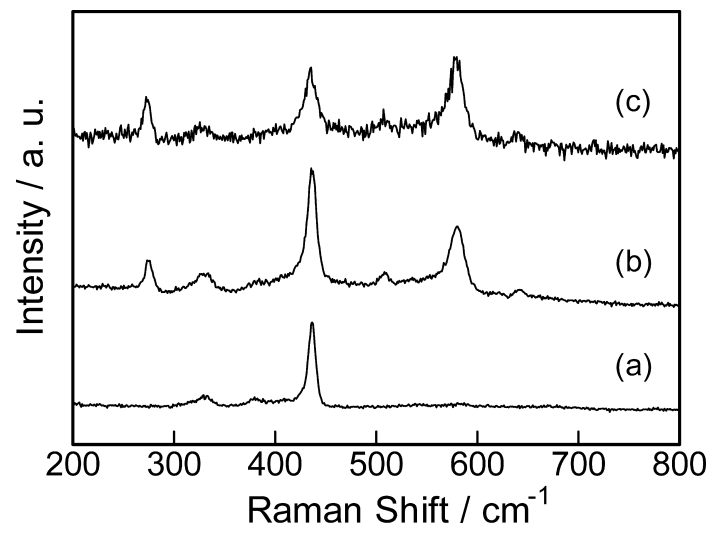

Fig. 3. Raman spectra of the particles obtained by heating the mixture of zinc peroxide nanoparticles and $\mathrm{NH}_{4} \mathrm{NO}_{3}$ at $573 \mathrm{~K}$ for $1 \mathrm{~h}$. The molar ratios of $\mathrm{NH}_{4} \mathrm{NO}_{3} / \mathrm{Zn}^{2+}$ were: (a) 0 , (b) 0.1 and (c) 0.2 .
$\mathrm{Zn}^{2+}$ ion of the obtained nitrogen-doped $\mathrm{ZnO}$ was 0.0037 and 0.0068 , respectively. Accordingly, the results of the iodometric titration showed the presence of the acceptor states in the $\mathrm{ZnO}$ particles obtained by heating the mixture of zinc peroxide and $\mathrm{NH}_{4} \mathrm{NO}_{3}$. The formation of acceptor states also indicated that the nitrogen-doping successfully occurred. Furthermore, the number of the acceptor states per $\mathrm{Zn}^{2+}$ ion increased with the increase of the molar ratio of $\mathrm{NH}_{4} \mathrm{NO}_{3} / \mathrm{Zn}^{2+}$ in the mixture of the zinc peroxide nanoparticles and $\mathrm{NH}_{4} \mathrm{NO}_{3}$. The doped amount of nitrogen can be regulated by the molar ratio of $\mathrm{NH}_{4} \mathrm{NO}_{3} / \mathrm{Zn}^{2+}$ in the mixture.

In order to further examine the details of the obtained $\mathrm{ZnO}$ particles, the UV-VIS absorption spectra were measured, as shown in Figs. 4(a)-(e). The strong absorption around $400 \mathrm{~nm}$ corresponds to the electron transition between the band gap of ZnO. The UV-VIS absorption spectra in Figs. 4(b)-(e) have other broad shoulder peaks from $400 \mathrm{~nm}$ to $700 \mathrm{~nm}$. The intensity of these broad peaks increased with increases in the molar ratio of

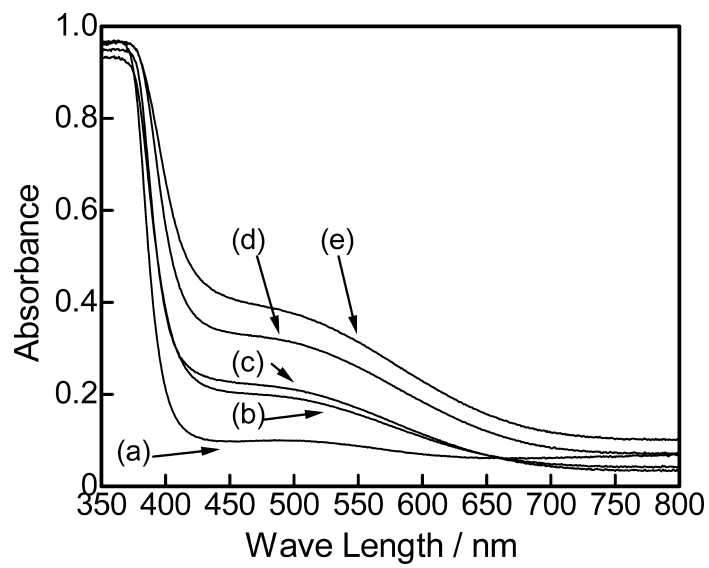

Fig. 4. UV-VIS spectra of the particles obtained by heating the mixture of $\mathrm{NH}_{4} \mathrm{NO}_{3}$ and zinc peroxide nanoparticles at $573 \mathrm{~K}$ for $1 \mathrm{~h}$. The molar ratios of $\mathrm{NH}_{4} \mathrm{NO}_{3} / \mathrm{Zn}^{2+}$ were: (a) 0.05 , (b) 0.1 , (c) 0.15 , (d) 0.2 and (e) 0.25 .

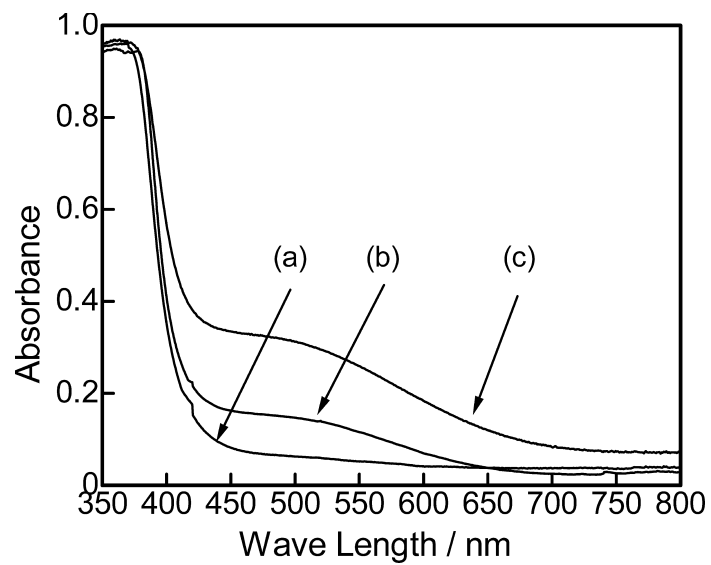

Fig. 5. UV-VIS absorption spectra of the particles obtained by heating the powders in the air at $573 \mathrm{~K}$ for $1 \mathrm{~h}$. The heated powders were: (a) the powder obtained by drying the zinc peroxide sol, (b) the mixed powder of $\mathrm{NH}_{4} \mathrm{NO}_{3}$ and the zinc peroxide powder obtained by drying the zinc peroxide sol, and (c) the powder obtained by drying the mixture of the zinc peroxide sol and $\mathrm{NH}_{4} \mathrm{NO}_{3}$. The molar ratio of $\mathrm{NH}_{4} \mathrm{NO}_{3} / \mathrm{Zn}^{2+}=0.2$. 

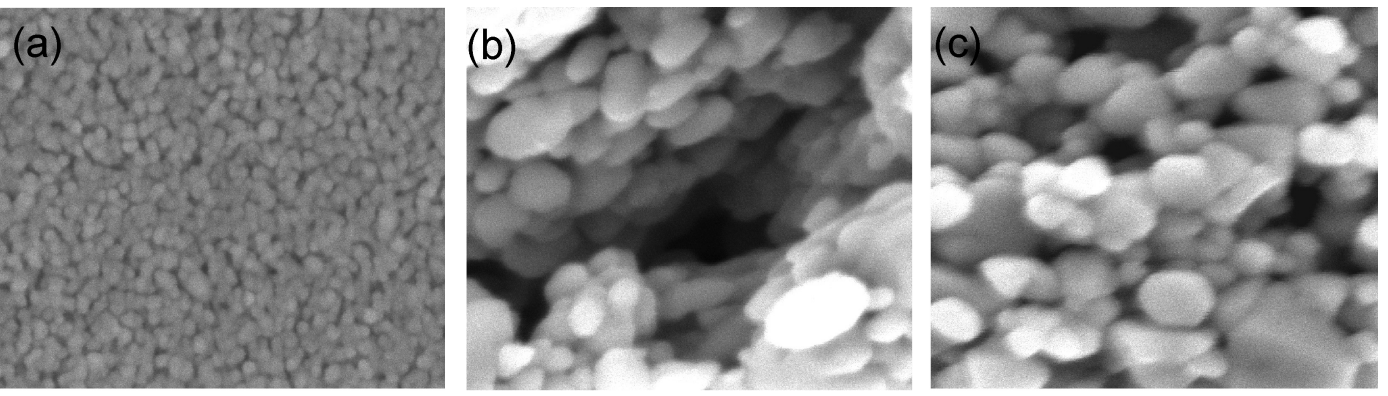

\section{$100 \mathrm{~nm}$}

Fig. 6. FE-SEM images of the particles obtained by heating the mixture of zinc peroxide nanoparticles and $\mathrm{NH}_{4} \mathrm{NO}_{3}$ at $573 \mathrm{~K}$ for $1 \mathrm{~h}$. The molar ratios of $\mathrm{NH}_{4} \mathrm{NO}_{3} / \mathrm{Zn}^{2+}$ were: (a) 0 , (b) 0.1 and (c) 0.2 .

$\mathrm{NH}_{4} \mathrm{NO}_{3} / \mathrm{Zn}^{2+}$. Accordingly, the broad absorption peaks from $400 \mathrm{~nm}$ to $700 \mathrm{~nm}$ corresponded to the impurity states formed by nitrogen-doping. The substitution of nitrogen for the oxygen successively occurred and the change in the electronic structure affected the UV-VIS absorption spectra. Therefore, nitrogendoped $\mathrm{ZnO}$ particles can be obtained by a relatively lowtemperature heating process at $573 \mathrm{~K}$ in air. Furthermore, the simple preparation process of the nitrogen-doped $\mathrm{ZnO}$ particles was enabled by using zinc peroxide nanoparticles and ammonium salts as a precursor.

In order to examine the effect of the mixing the zinc peroxide nanoparticles and $\mathrm{NH}_{4} \mathrm{NO}_{3}$ in the aqueous sol on the nitrogen doping, the UV-VIS adsorption spectrum of the $\mathrm{ZnO}$ powders obtained by heating the dried mixture of the zinc peroxide sol and $\mathrm{NH}_{4} \mathrm{NO}_{3}$ was compared with that of the mixture of $\mathrm{NH}_{4} \mathrm{NO}_{3}$ powder and the zinc peroxide powder obtained by drying the zinc peroxide sol. In this case, the mixing was carried out by using an agate mortar and a pestle. The UV-VIS absorption spectra were shown in Figs. 5(a)-(c). The drying condition was at 348 $\mathrm{K}$ for $12 \mathrm{~h}$ and the heating condition was at $573 \mathrm{~K}$ for $1 \mathrm{~h}$. The molar ratio of $\mathrm{NH}_{4} \mathrm{NO}_{3} / \mathrm{Zn}^{2+}$ was 0.2 . The UV-VIS absorption spectrum in Fig. 5(b) has the broad shoulder peaks from $400 \mathrm{~nm}$ to $700 \mathrm{~nm}$ which corresponded to the nitrogen-doping as compared with the spectrum shown in Fig. 5(a). This result suggests that the nitrogen-doped $\mathrm{ZnO}$ was obtained by heating the mixture of $\mathrm{NH}_{4} \mathrm{NO}_{3}$ powder and the zinc peroxide powder obtained by drying the zinc peroxide sol. Furthermore, the absorption intensity of this broad peak shown in Fig. 5(c) was stronger than that shown in Fig. 5(b). This result suggests that the doped amount of nitrogen in the particles obtained by heating the powder prepared by drying the mixture of the zinc peroxide sol and $\mathrm{NH}_{4} \mathrm{NO}_{3}$ were larger than that obtained by heating the mixture of $\mathrm{NH}_{4} \mathrm{NO}_{3}$ powder and the zinc peroxide powder. Therefore, the formation of the homogeneous mixed state in the aqueous sol was important to obtain the nitrogen-doped $\mathrm{ZnO}$ particles.

The particle morphology reflects the formation process of the nitrogen-doped $\mathrm{ZnO}$ particles. Therefore, the FE-SEM images of the obtained $\mathrm{ZnO}$ particles were examined. Figure 6(a) shows the FE-SEM image of the $\mathrm{ZnO}$ particles obtained by heating the zinc peroxide nanoparticles at $573 \mathrm{~K}$ for $1 \mathrm{~h}$. The average particle size of the obtained $\mathrm{ZnO}$ particles was $27 \mathrm{~nm}$. In contrast, the average diameters of the nitrogen-doped $\mathrm{ZnO}$ particles obtained by the mixture of $\mathrm{NH}_{4} \mathrm{NO}_{3}$ and the zinc peroxide nanoparticles in Figs. 6(b) and (c) were $105 \mathrm{~nm}$ and $120 \mathrm{~nm}$, respectively. The average diameters of the obtained $\mathrm{ZnO}$ particles from the mixture of the zinc peroxide nanoparticles and $\mathrm{NH}_{4} \mathrm{NO}_{3}$ were larger than those obtained from the zinc peroxide nanoparticles, though

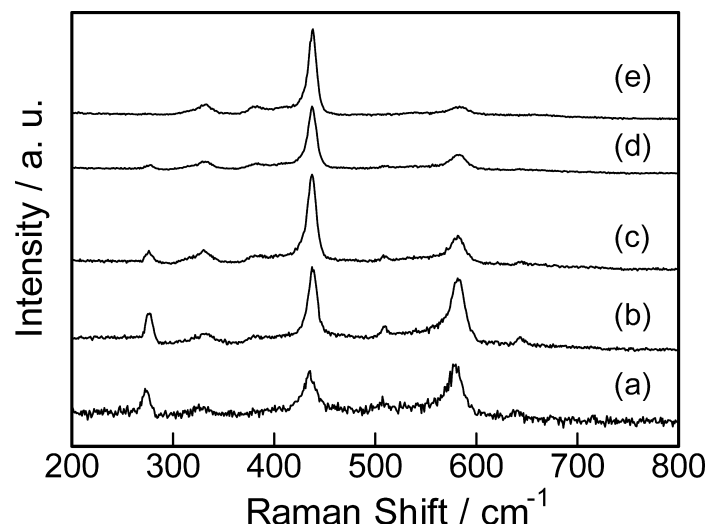

Fig. 7. Raman spectra of the nitrogen-doped $\mathrm{ZnO}$ particles heated in air for $1 \mathrm{~h}$. The nitrogen-doped $\mathrm{ZnO}$ particles were prepared by heating the mixture of zinc peroxide nanoparticles and $\mathrm{NH}_{4} \mathrm{NO}_{3}$ at $573 \mathrm{~K}$ for $1 \mathrm{~h}$. The molar ratio of $\mathrm{NH}_{4} \mathrm{NO}_{3} / \mathrm{Zn}^{2+}$ was 0.2 . The heating temperatures were: (a) $573 \mathrm{~K}$, (b) $773 \mathrm{~K}$, (c) $873 \mathrm{~K}$, (d) $973 \mathrm{~K}$ and (e) $1073 \mathrm{~K}$.

the heating temperature was same as that shown in Fig. 6(a). $\mathrm{ZnO}$ particles with an average diameter greater than $100 \mathrm{~nm}$ can be obtained by heating the zinc peroxide nanoparticles to more than $1073 \mathrm{~K}$, as previously reported in our literature. In general, $\mathrm{NH}_{4} \mathrm{NO}_{3}$ melts around $443 \mathrm{~K}^{.17)}$ It is therefore considered that the acceleration of the grain growth in the mixture of the zinc peroxide nanoparticles and $\mathrm{NH}_{4} \mathrm{NO}_{3}$ is related to the rapid diffusion process in the molten salt. The dissolution-precipitation process in the molten salt affects the grain growth and the nitrogen-doping process. Accordingly, the ammonium salt played an important role not only as a nitrogen source but also in the formation of the reaction atmosphere.

The effect of heating the nitrogen-doped $\mathrm{ZnO}$ particles in air was also examined. Figure 7 shows the Raman spectra of the nitrogen-doped $\mathrm{ZnO}$ particles heated in air for $1 \mathrm{~h}$. The nitrogendoped $\mathrm{ZnO}$ particles that were heated in air were prepared by heating the mixture of the zinc peroxide nanoparticles and $\mathrm{NH}_{4} \mathrm{NO}_{3}\left(\mathrm{NH}_{3} \mathrm{NO}_{3} / \mathrm{Zn}^{2+}=0.2\right.$ molar ratio $)$ at $573 \mathrm{~K}$ for $1 \mathrm{~h}$. The Raman peak at $437 \mathrm{~cm}^{-1}$ in Fig. 7(a) can be assigned to the lattice vibrational mode of $\mathrm{ZnO}$. The Raman peaks at $275 \mathrm{~cm}^{-1}$ and 583 $\mathrm{cm}^{-1}$ in Fig. 7(a) can be assigned to the nitrogen-related local vibration modes. When the nitrogen-doped $\mathrm{ZnO}$ particles were heated at $773 \mathrm{~K}$ for $1 \mathrm{~h}$ in the air, the peak intensity of the nitrogen-related vibration modes at $275 \mathrm{~cm}^{-1}$ and $583 \mathrm{~cm}^{-1}$ decreased relatively slightly as compared with the lattice vibrational mode of $\mathrm{ZnO}$ at $437 \mathrm{~cm}^{-1}$. Furthermore, when the heating 


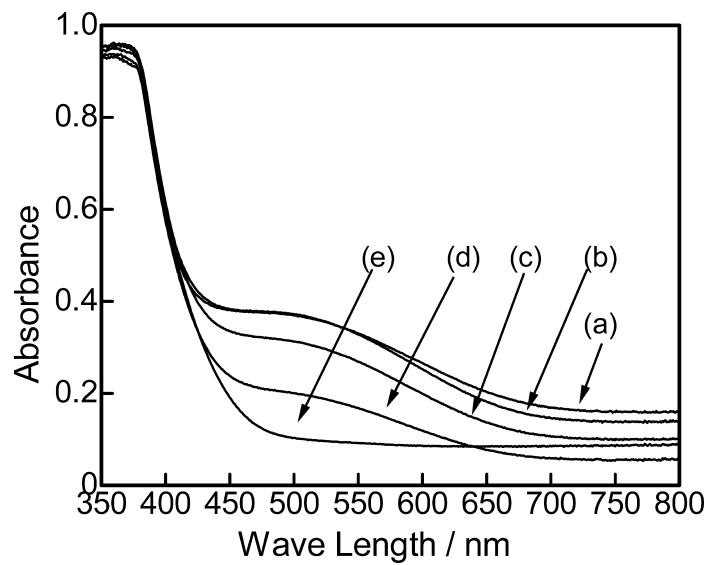

Fig. 8. UV-VIS absorption spectra of the nitrogen-doped $\mathrm{ZnO}$ particles heated in the air for $1 \mathrm{~h}$. The heated nitrogen-doped $\mathrm{ZnO}$ particles were prepared by heating the mixture of zinc peroxide nanoparticles and $\mathrm{NH}_{4} \mathrm{NO}_{3}$ at $573 \mathrm{~K}$ for $1 \mathrm{~h}$. The molar ratio of $\mathrm{NH}_{4} \mathrm{NO}_{3} / \mathrm{Zn}^{2+}$ was 0.2 . The heating temperatures were: (a) $573 \mathrm{~K}$, (b) $773 \mathrm{~K}$, (c) $873 \mathrm{~K}$, (d) $973 \mathrm{~K}$ and (e) $1073 \mathrm{~K}$.

temperature increased from $773 \mathrm{~K}$ to $973 \mathrm{~K}$, the intensity of the peaks corresponding to the nitrogen-related local vibration modes greatly decreased as compared with the $\mathrm{ZnO}$ lattice vibrational mode, as shown in Figs. 7(b)-(d). This result indicated that the heating of the nitrogen-doped $\mathrm{ZnO}$ particles in air caused a substitution of the nitrogen atoms in the nitrogen-doped $\mathrm{ZnO}$ particles to oxygen atoms. Furthermore, as shown in Fig. 7(e), the whole Raman peaks in the spectra of the nitrogen-doped $\mathrm{ZnO}$ particles heated at $1073 \mathrm{~K}$ for $1 \mathrm{~h}$ can be assigned to the $\mathrm{ZnO}$ lattice vibrational mode. Accordingly, the heating of the nitrogen-doped $\mathrm{ZnO}$ at $1073 \mathrm{~K}$ caused a substitution of oxygen atoms for the whole nitrogen atoms in the nitrogen-doped $\mathrm{ZnO}$ particles.

In order to clarify the effects of heating in air, the UV-VIS spectra were also examined. Figures 8(a)-(e) show the UV-VIS absorption spectra of the nitrogen-doped $\mathrm{ZnO}$ particles heated for $1 \mathrm{~h}$. These spectra show a strong absorption around $400 \mathrm{~nm}$ corresponding to the electron transition between the band gap of $\mathrm{ZnO}$ and other broad shoulder peaks from $400 \mathrm{~nm}$ to $700 \mathrm{~nm}$ corresponding to the impurity states formed by the nitrogen-doping. This result in the UV-VIS spectrum agrees with the Raman spectrum shown in Fig. 7(a). Furthermore, the strength of the absorption, which corresponds to the impurity state of the nitrogen-doping from $400 \mathrm{~nm}$ to $700 \mathrm{~nm}$, gradually decreased when the heating temperature increased in a range from $573 \mathrm{~K}$ to 973 K, as shown in Figs. 8(a)-(d). Finally, when the nitrogendoped $\mathrm{ZnO}$ was heated at $1073 \mathrm{~K}$ for $1 \mathrm{~h}$, no absorption corresponding to the impurity states appeared in the spectrum shown in Fig. 8(e). Accordingly, this result indicates that the substitution of oxygen for nitrogen successfully occurred by heating in air at $1073 \mathrm{~K}$ for $1 \mathrm{~h}$ and that pure $\mathrm{ZnO}$ particles were obtained. As shown in Fig. 7(e), the Raman spectrum of the nitrogendoped $\mathrm{ZnO}$ particles heated at $1073 \mathrm{~K}$ for $1 \mathrm{~h}$ also supports the above result.

\subsection{Effect of the ammonium salts mixed with the zinc peroxide nanoparticles on the nitrogen- doping}

In order to examine the effects of anions in the ammonium salts mixed with the zinc peroxide nanoparticles on the nitrogen-

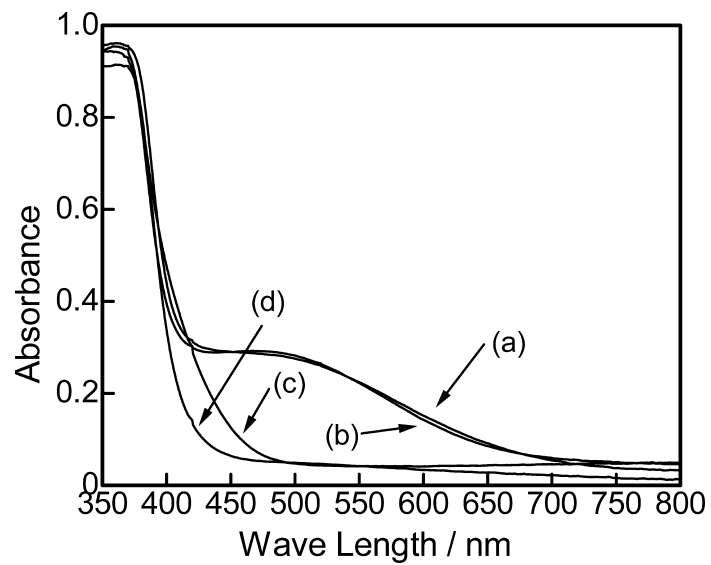

Fig. 9. UV-VIS absorption spectra of the particles obtained by heating the mixture of zinc peroxide nanoparticles and ammonium salts at $573 \mathrm{~K}$ for $1 \mathrm{~h}$. The molar ratio of ammonium salts $/ \mathrm{Zn}^{2+}$ was 0.2 . The used ammonium salts were: (a) $\mathrm{NH}_{4} \mathrm{NO}_{3}$, (b) $\left(\mathrm{NH}_{4}\right)_{2} \mathrm{C}_{2} \mathrm{O}_{4}$, (c) $\mathrm{NH}_{4} \mathrm{Cl}$, and (d) $\mathrm{NH}_{4}\left(\mathrm{CH}_{3} \mathrm{COO}\right)$.

doping, the UV-VIS absorption spectra of the particles obtained by heating a mixture of zinc peroxide nanoparticles and ammonium salts at $573 \mathrm{~K}$ for $1 \mathrm{~h}$ were measured. When the mixtures with ammonium nitrate $\left(\mathrm{NH}_{4} \mathrm{NO}_{3}\right)$ or ammonium oxalate $\left(\left(\mathrm{NH}_{4}\right)_{2} \mathrm{C}_{2} \mathrm{O}_{4}\right)$ were heated, the UV-VIS absorption spectra of the obtained particles had a broad shoulder peak from $400 \mathrm{~nm}$ to 700 $\mathrm{nm}$ corresponding to the nitrogen-doping, as shown in Figs. 9(a) and (b). Accordingly, the results indicate that the nitrogendoping successfully occurred in the above cases. In particular, the nitrogen-doped $\mathrm{ZnO}$ was obtained when the mixture of ammonium oxalate and zinc peroxide nanoparticles was used even though the nitrogen was only included in ammonium ion of ammonium oxalate. This result indicated that the nitrogen atoms in the nitrogen-doped $\mathrm{ZnO}$ were supplied from the ammonium ions in the ammonium salts.

In contrast, when the mixture with ammonium chloride $\left(\mathrm{NH}_{4} \mathrm{Cl}\right)$ and ammonium acetate $\left(\mathrm{NH}_{4}\left(\mathrm{CH}_{3} \mathrm{COO}\right)\right)$ was heated, the UV-VIS absorption spectra of the obtained particles did not have any shoulder peak from $400 \mathrm{~nm}$ to $700 \mathrm{~nm}$ and the only strong absorption appeared around $400 \mathrm{~nm}$, which corresponds to the electron transition between the band gap, as shown in Figs. 9(c) and (d). These results on the UV-VIS spectra indicate that the particles obtained by heating the mixture of the zinc peroxide nanoparticles and ammonium chloride or ammonium acetate were $\mathrm{ZnO}$ particles without nitrogen-doping. Accordingly, the nitrogen-doping of the obtained $\mathrm{ZnO}$ particles depended on the ammonium salt heated with the zinc peroxide. In a previous paper, the authors showed that the thermal decomposition of zinc peroxide forms zinc oxide with oxygen vacancies. ${ }^{18)}$ The decomposition of the zinc peroxide is a disproportionate reaction: $\mathrm{O}_{2}{ }^{2-} \rightarrow \mathrm{O}^{2-}+1 / 2 \mathrm{O}_{2}$. As previously shown, this reaction can be divided into a reduction reaction and an oxidation reaction: $\mathrm{O}_{2}{ }^{2-} \rightarrow \mathrm{O}_{2}+2 \mathrm{e}^{-}$and $\mathrm{O}_{2}{ }^{2-}+2 \mathrm{e}^{-} \rightarrow 2 \mathrm{O}^{2-}$. ${ }^{2)}$ When the $\mathrm{O}_{2}{ }^{2-}$ ions in the oxide lattice decompose, oxygen vacancies are formed by the reduction reaction of $\mathrm{O}_{2}{ }^{2-} \rightarrow \mathrm{O}_{2}+2 \mathrm{e}^{-}$since the $\mathrm{O}_{2}{ }^{2-}$ ions in the lattice are lost to form $\mathrm{O}_{2}$ molecules in the gas phase. As shown in Figs. 9(c) and (d), in the case that ammonium chloride or ammonium acetate are mixed with the zinc peroxide nanoparticles, the particles obtained by heating the mixture at $573 \mathrm{~K}$ for $1 \mathrm{~h}$ are $\mathrm{ZnO}$ particles without nitrogen-doping. This result indicates that the $\mathrm{O}_{2}{ }^{2-}$ ions react with the acetate ions and chloride 
ions in the ammonium salts as oxidizing agents. Then, the reaction of $\mathrm{O}_{2}{ }^{2-}$ ions as a reduction agent $\left(\mathrm{O}_{2}{ }^{2-} \rightarrow \mathrm{O}_{2}+2 \mathrm{e}^{-}\right)$cannot occur, and oxygen vacancies in the $\mathrm{ZnO}$ lattice therefore do not form. However, the formation of oxygen vacancies is required for nitrogen-doping. Therefore, when the ammonium acetate and ammonium chloride were used, nitrogen-doping did not occur, as shown in Figs. 9(c) and (d). In contrast, in the case that ammonium oxalate and ammonium nitrate were mixed with the zinc peroxide nanoparticles, the particles obtained by heating the mixture at $573 \mathrm{~K}$ for $1 \mathrm{~h}$ were nitrogen-doped $\mathrm{ZnO}$ particles, as shown in the Figs. 9(a) and (b). The oxalate ions and nitrate ions did not react with the $\mathrm{O}_{2}{ }^{2-}$ ions in the zinc peroxide so that the dominant process of the decomposition of the $\mathrm{O}_{2}{ }^{2-}$ ions became a reduction reaction $\left(\mathrm{O}_{2}{ }^{2-} \rightarrow \mathrm{O}_{2}+2 \mathrm{e}^{-}\right)$. ${ }^{19)}$ Therefore, the oxygen vacancies formed by the decomposition of the $\mathrm{O}_{2}{ }^{2-}$ ions played an important role in nitrogen-doping.

\section{Conclusion}

Nitrogen-doped $\mathrm{ZnO}$ particles were prepared by heating a mixture of ammonium salts and the aqueous sol of zinc peroxide nanoparticles. In the case that the aqueous sol of zinc peroxide nanoparticles were mixed with ammonium nitrate, the nitrogendoped $\mathrm{ZnO}$ was obtained by heating the mixture at $573 \mathrm{~K}$ for $1 \mathrm{~h}$. The obtained particles showed characteristic Raman peaks that can be assigned to the nitrogen-related local vibrational mode. The strength of the UV-VIS absorption peak, which can be assigned to the nitrogen-related impurity state, also increased with increases in the mixed amount of ammonium nitrate. The homogenous mixture of the zinc peroxide nanoparticles and ammonium salts in the aqueous sol and the homogeneous dispersion of ammonium salts on the surface of the zinc peroxide played an important role for the nitrogen doping. According to the FE-SEM images of the nitrogen-doped $\mathrm{ZnO}$ particles, even if the heating temperature of the mixture was $573 \mathrm{~K}$, relatively large particles were observed. This result indicates that a rapid grain growth process took place in the molten salt of the ammonium nitrate. In addition, the effects of anions in the ammonium salts on the nitrogen-doping were investigated. In the case that the $\mathrm{O}_{2}{ }^{2-}$ ions in the zinc peroxide nanoparticles reacted with the anions to form oxygen vacancies, nitrogen-doping successfully occurred. Accordingly, the role of $\mathrm{O}_{2}{ }^{2-}$ ions as a reducing agent is important for nitrogen-doping.
Acknowledgement This research was supported by the Science Research Grant from the Ministry of Education, Culture, Sports, Science and Technology, Japanese Government.

\section{References}

1) G. Thomas, Nature, 389, 907 (1997).

2) H. Ohta, K. Kawamura, M. Orita, N. Sarukura, M. Hirano and H. Hosono, J. Appl. Phys., 89, 5720-5725 (2001).

3) H. F. Chen, H. J. Ko, S. K. Hong and T. Yao, Appl. Phys. Lett., 76, 559-561 (2000).

4) S. M. Lukas and L. M. Judith, Mater. Today, 10, 40-48 (2007).

5) M. H. Huang, S. Mao, H. Feick, H. Q. Yan, Y. Y. Yu, H. Kind, R. Russo and P. D. Yang, Science, 292, 1897-1899 (2001).

6) J. Li, R. Kykyneshi, J. Tate and A. W. Sleight, Solid State Sci., 9, 613-618 (2007).

7) D. C. Look, D. C. Reynolds, C. W. Litton, R. L. Jones, D. B. Eason and G. Cantwell, Appl. Phys. Lett., 81, 1830-1832 (2002).

8) S. B. Zhang, S. Huai and A. Zunger, J. Appl. Phys., 83, 3192-3196 (1998).

9) W. Wang, S. Yang, J. Wang, M. Li, X. Jiang, G. Du, X. Liu and R. P. H. Chang, J. Cryst. Growth, 226, 123-129 (2001).

10) J. Lu, Z. Ye, L. Wang, J. Huang and B. Zhao, Mater. Sci. Semi. Processing, 5, 491-496 (2003).

11) N. Varghese, L. S. Panchakarla, M. Hanapi, A. Govindaraj and C. N. R. Rao, Mater. Res. Bull., 42, 2117-2124 (2007).

12) N. Uekawa, N. Mochizuki, J. Kajiwara and K. Kakegawa, Phys. Chem. Chem. Phys., 5, 929-934 (2003).

13) N. Uekawa, J. Kajiwara, N. Mochizuki, K. Kakegawa and Y. Sasaki, Chem. Lett., 2001, 606-607 (2001).

14) D. C. Harris, M. E. Hills and T. A. Hewston, J. Chem. Educ., 64, 847-850 (1987).

15) A. Kaschner, U. Haboeck, M. Strassburg, G. Kaczmarczyk, A. Zeuner, H. R. Alves, D. M. Hofman and B. K. Meyer, Appl. Phys. Lett., 80, 1909-1911 (2002).

16) L. L. Kerr, X. Li, M. Canepa and A. J. Sommer, Thin Solid Films, 515, 5282-5286 (2007).

17) C. N. R. Rao and K. J. Rao, Prog. in Solid State Chem., 4, 131-185 (1967).

18) T. X. Wang and T. J. Lou, Mater. Lett., 62, 2329-2331 (2008).

19) N. Uekawa, T. Kudo, Y. J. Wu and K. Kakegawa, J. Ceram. Soc. Japan, Suppl., 112, S37-S40 (2004). 